\title{
Gebe Kadınların Gebelikte Yoganın Faydaları Hakkındaki Bilgi ve Görüşleri
}

\author{
Zeliha Burcu YURTSAL ${ }^{1}$, Vasviye EROĞLU ${ }^{2}$ \\ 1 Cumhuriyet Üniversitesi Sağlık Bilimleri Fakültesi, Ebelik Bölümü, Sivas. \\ 2 Gaziosmanpaşa Üniversitesi, Artova Meslek Yüksekokulu, Engelli Bakımı ve Rehabilitasyon Bölümü, Tokat.
}

\section{ÖZET}

Giderek artan popülaritesine rağmen, gebe kadınlarda yoganın faydaları hakkında bilgi ve görüşlerini belirleyen sınırlı sayıda çalışma yapılmıştır. Bu çalışmanın amacı, gebe kadınların gebelikte yoga hakkında bilgi ve görüşlerini belirleyerek konu hakkında farkındalık oluşturmaktır. Tanımlayıcı kesitsel tipteki araștırma bir üniversite hastanesi’nin kadın doğum polikliniklerinde yapılmıștır. 15 Ocak- 15 Mart 2019 tarihleri arasında polikliniğe başvuran tüm gebeler çalışmaya alınmış, 220 gebeye ulaşılmıştır. Veriler araştırmacı tarafindan geliştirilen 34 sorudan oluşan Kişisel Bilgi ve Yoga Bilgi Düzeyi Formu ile toplanmıștır. Elde edilen verilerin istatistiksel değerlendirmesi bilgisayar ortamında SPSS 22.0 paket programı ile yapılmıștır. Gebelerin \%76,4'ünün $(\mathrm{n}=168)$ gebelik kontrollerinin ağılıklı olarak doktor tarafindan yapıldığı gözlenmiştir. Gebelerin gebeliklerinin kendisinde anksiyete oluşturduğunu söyleme oranı \%74,5'inin (n=164), doğum korkusu yaşama oranı \%68,1 (n=150) olarak belirlenmiștir. Gebelerin \%88'6's1 (n=195) gebelikte egzersiz yapmanın gerekli olduğunu düșünmesine rağmen, \%60,5'inin ( $\mathrm{n}=132)$ gebeliğinde düzenli olarak egzersiz yapmadığı saptanmıștır. Gebelerin \%91'i $(\mathrm{n}=201)$ gebelikte en uygun egzersizin yürüyüş, \%54'ü $(n=120)$ solunum egzersizleri, $\% 30$ 'u $(n=67)$, pilates, $\% 26$ 'sı $(n=57)$ yüzme, $\% 24 ' u ̈ ~(n=54)$ ise yoga olduğunu düşünmektedirler. Birden fazla tercih edenler olmuştur. Yoga uygulamalarının olumlu sonuçlarına rağmen gebe kadınların konu ile ilgili bilgi ve bilinç düzeyinin istenen düzeyde olmadığı tespit edilmiştir. Özellikle ebelerin gebelere yönelik yoga alanında eğitimlerini ve çalışmalarını yoğunlaştırmasının, yoganın gebelik doğum ve doğum sonu dönemdeki olumlu çıktılarını destekleyecek uygulamalı araştırmalar yapması ile ebelik alanına katkı sağlanacağı düşünülmektedir.

Anahtar Kelimeler: Gebe kadınlar. Gebelikte yoga. Yoganın faydaları. Ebelik.

Knowledge and Opinions of Pregnant Women about the Benefits of Yoga in Pregnancy

\section{ABSTRACT}

Despite its increasing popularity, limited number of studies have been conducted to determine the knowledge and opinions about the benefits of yoga in pregnant women. The aim of this study was to determine the knowledge and opinions of pregnant women about yoga during pregnancy and to raise awareness about the subject. This descriptive cross-sectional study was conducted in a gynecology outpatient clinic of a University Hospital. All pregnant women who applied to the outpatient clinic between January 15 and March 15, 2019 were included in the study and 220 pregnant women were reached. Data were collected by Personal Knowledge and Yoga Knowledge Level Form which consisted of 34 questions developed by the researcher. The statistical evaluation of the data was done by SPSS 22.0 package program on computer. It was observed that $76.4 \%(n=168)$ of the pregnancies were performed mostly by the physician. It was determined that $74.5 \%(n=164)$ of pregnant women had anxiety in their pregnancy and $68.1 \%(\mathrm{n}=150)$ of fear of birth. Although $88.6 \%(\mathrm{n}=195)$ of the pregnant women thought that exercise was necessary during pregnancy, 60.5\% $(n=132)$ did not exercise regularly during pregnancy. $91 \%(n=201)$ of the pregnant women were the most suitable exercise during gait, $54 \%(\mathrm{n}=120)$ breathing exercises, $30 \%(\mathrm{n}=67)$, pilates, $26 \%(\mathrm{n}=57)$ swimming $24 \%(n=54)$ think that yoga. There have been more than one. Despite the positive results of yoga practices, it was found that the level of knowledge and awareness of pregnant women about the subject was not at the desired level. It is thought that midwives will concentrate on their training and studies in the field of yoga for pregnant women, and practical studies that will support the positive outcomes of yoga during pregnancy and postpartum period will contribute to midwifery field.

Key Words: Pregnant women. Yoga during pregnancy. Benefits of yoga. Midwifery

Geliş Tarihi: 19 Eylül 2019

Kabul Tarihi: 27 Kasım 2019

* Bu çalışma, 6. Uluslararası 10. Ulusal Ebelik Öğrencileri Kongresi'nde sözel bildiri olarak sunulmuştur (19-21 Nisan 2019, Sivas).

Dr. Zeliha Burcu YURTSAL

Cumhuriyet Üniversitesi

Sağlık Bilimleri Fakültesi

Ebelik Bölümü,

58140, Kampüs, Sivas

Tel.:0532 3378084

E-posta:burcuyurtsal@hotmail.com
Yoga, sağlığın fiziksel, duygusal, zihinsel ve ruhsal yönlerini dengeleme potansiyeli sahip eski bir uygulamadır (Curtis, Weinrib, \& Katz, 2012). Derin nefes alma (pranayama), postür (asana) ve konsantrasyon (meditasyon) üçlüsünden oluşan bir zihin beden uygulamasıdır (Wile, 2013). Yoga, Hindistan'da ortaya çıkmış ve çeşitli ülkelerde fiziksel etkilerinin yanı sıra stres ve kaygı azaltıcı, ruh halini iyileştirici, refah düzeyini artırıcı, kilo kontrolü sağlayıcı özelliklerinden dolayı giderek daha fazla tanınan ve kullanılan bir zihin-beden pratiği haline gelmiştir (Curtis, Weinrib, 
\& Katz, 2012; Yadav \& Kumar, 2015; Kumar \& Patel, 2016; Riley \& Park, 2015).

Gebelik, kadının hayatını fiziksel, zihinsel, duygusal ve ruhsal olarak değiştiren bir süreçtir (Thakur, Sharma, \& Masand, 2015). Gebenin, fiziksel, ruhsal veya psikososyal boyutunda oluşan bozulma, anne ve bebek üzerinde olumsuz etkilere neden olabilmektedir. Annenin yaşadığı stres ve anksiyete, spontan düşük, intrauterin büyüme geriliği (IUGR), erken doğum ve preeklampsi gibi gebelik sonuçlarına yol açmaktadır. Literatürde maternal stres sezaryen doğum (Olieman, Siemonsma, Bartens, \& Honig, 2017) ve normal doğum sırasında analjezik kullanımının artmasıyla ilişkilendirilmiştir (Riley \& Drake, 2013). Ayrıca gebelik döneminde yaşanan bel ve sırt ağrıları, bacaklarda oluşan ödem ve kramplar, ilerleyen gebelik haftalarında büyüyen abdomenin yapmış olduğu basınca bağlı solunum problemleri ve uyku bozuklukları gebenin yaşam kalitesini olumsuz olarak etkilemektedir. Yoga tüm bu boyutları dengeleyerek, normal, komplikasyonsuz bir gebelik, doğum ve doğum sonrası deneyimi yaşatmaya yönelik olumlu çıktılara yol açtığı, yan etkisi olmadığı ve gebelere uyarlanabilirliği giderek artmaktadır (Thakur, Sharma, \& Masand, 2015; Başmeşe, 2017; Marc, et al., 2011).

Yoga pranayamaları (Nefes teknikleri) ve asenaları (duruşlar)vücudu güçlendirerek otomatik olarak kad1nın doğuma hazırlanmasının öğretildiği bir uygulamadır. Gebelikte uygulanan yoga asenaları, denge ve sirt kuvveti oluşturmada, kalça esnekliği ve nefes kontrolü kazandırarak doğum ve postpartum süreçte annelerin sakinleşmesine yardımcı olmakta ve anne bebek ilişkisini arttırmaktadır (Thakur, Sharma, \& Masand, 2015; Akarsu \& Rathfsch, 2018; Chhajta, 2018).

Gebelik döneminin son haftalarında ebelik uygulamalarının temelinde, gebenin rahatını, doğuma ruhsal, bedensel ve zihinsel hazırlanmasını sağlamak ve bebeğin doğru pozisyonda doğum kanalına yerleşmesini desteklemek yer almaktadır. Gebelikte yapılan yoga uygulamaları, gebeyi doğum ve sonrası döneme fiziksel ve zihinsel olarak hazırlayacağı gibi gebenin doğum eyleminde ihtiyaç duyacağı içsel öz yeterliliğe ulaşmasını da kolaylaştıracaktır. Yoga gebenin kendi merkezinde kalmasına ve bebeğiyle iletişimde olmas1na yardımcı olacaktır (Akarsu \& Rathfsch, 2018; Sharma \& Branscum, 2015).

Giderek artan popülaritesine rağmen, gebe kadınlarda yoganın faydaları hakkında bilgi ve görüşlerini belirleyen sınırlı sayıda çalışma yapılmıştır. Bu çalışmanın amacı, gebe kadınların gebelikte yoga hakkında bilgi ve görüşlerini belirleyerek konu hakkında farkındalık oluşturmaktır. Bununla birlikte bu çalışmanın ebelik uygulamalarına yogayı dahil ederek yapılacak yeni çalışmalara katkı sağlayacağı düşünülmektedir.

\section{Gereç ve Yöntem}

Tanımlayıcı kesitsel tipteki araştırma bir üniversite hastanesi'nin kadın doğum polikliniklerinde yapılmıştır. 15 Ocak- 15 Mart 2019 tarihleri arasında polikliniğe başvuran tüm gebeler çalışmaya alınmış, 220 gebeye ulaşılmıştır. Araştırmaya katılmayı gönüllü olarak kabul eden, 18 yaş üzeri, okuma yazması olan gebeler çalışmaya dahil edilmiştir. Veriler araştırmacı tarafından geliştirilen 35 sorudan oluşan Kişisel Bilgi ve Yoga Bilgi Düzeyi Formu (yaş, eğitim ve çalışma durumu gibi kişisel sorular ve yoganın gebelikte, doğum ve doğum sonu dönem ve yenidoğan dönemlerine olan etkileri ve faydaları hakkında sorular) ile toplanmıştır. Çalışmanın uygulanması için, Etik Kurulu onayı Cumhuriyet Üniversitesi Girişimsel Olmayan Klinik Araştırmalar Etik Kurulu'ndan (karar no: 201812/33) alınmıştır. Elde edilen verilerin istatistiksel değerlendirmesi bilgisayar ortamında SPSS 22.0 paket programı ile yapılmıştır. Araştırmanın bulgularının değerlendirilmesinde tanımlayıcı istatistiksel analizler ve Ki-kare testi kullanılmıştır. Sonuçlar \%95'lik güven aralığında, anlamlılık $\mathrm{p}<0.05$ düzeyinde değerlendirilmiştir.

\section{Bulgular}

Çalışmaya katılan gebelerin yaş ortalamasının $29 \pm 5$,6olduğu belirlenmiştir. Gebelerin \%63,9'unun 24-34 yaş aralığında olduğu, \%41,4'ünün eğitim düzeyinin ortaöğretim olduğu ve $\% 56,4$ 'ünün çalışmad1ğ ve \%65,5'inin orta gelir düzeyine sahip olduğu saptanmıştır (Tablo I).

Tablo I. Gebelerin Sosyodemografik Özelliklerine Göre Dağılımı $(\mathrm{n}=220)$

\begin{tabular}{|l|c|c|}
\hline Değişkenler & $\mathbf{n}$ & $\%$ \\
\hline Yaş & 35 & 15,9 \\
24 yaş altı & 140 & 63,6 \\
24-34 yaş & 45 & 20,5 \\
\hline 35 ve üstü & & \\
\hline Eğitim & 91 & 41,4 \\
Ortaöğretim & 72 & 32,9 \\
Lise & 57 & 25,7 \\
Yükseköğretim & & \\
\hline Çalışma durumu & 96 & 43,6 \\
Evet & 124 & 56,4 \\
Hayır & & \\
\hline Gelir durumu & 40 & 18,2 \\
Gelir giderden az & 144 & 65,5 \\
Gelir gidere denk & 36 & 16,4 \\
\hline Gelir giderden fazla &
\end{tabular}




\section{Gebelikte Yoganın Faydaları}

Gebelerin \%76,4'ünün (n=168) gebelik kontrollerinin ağırlıklı olarak doktor tarafından yapıldığ 1 gözlenmiştir. Gebelerin gebeliklerinin kendisinde anksiyete oluşturduğunu söyleme oranı \%74,5'inin (n=164), doğum korkusu yaşama oranı \%68,1 $(n=150)$ olarak belirlenmiştir. Gebelerin \%88'6's1 (n=195) gebelikte egzersiz yapmanın gerekli olduğunu düşünmesine rağmen, \%60,5'inin $(n=132)$ gebeliğinde düzenli olarak egzersiz yapmadığı saptanmıştır (Tablo II). Gebelerin \%91'i $(n=201)$ gebelikte en uygun egzersizin yürüyüş, \%54'ü $(n=120)$ solunum egzersizleri, \%30'u $(n=67)$, pilates, \%26's1 $(n=57)$ yüzme, \%24'ü $(n=54)$ ise yoga olduğunu düşünmektedirler. Birden fazla tercih edenler olmuştur.

Tablo II. Gebelerin Bazı Özelliklerinin Dağılımı $(n=220)$

\begin{tabular}{|l|c|c|}
\hline Değişkenler & $\mathbf{n}$ & $\%$ \\
\hline Gebeliğinde en sık kontrole gittiği sağlık & & \\
personeli & & \\
Doktor & 168 & 76,4 \\
Ebe & 35 & 15,9 \\
Hemşire & 17 & 7,7 \\
\hline Gebeliğin anksiyete oluşturma durumu & & \\
Evet & 164 & 74,5 \\
Hayır & 52 & 23,6 \\
Fikrim Yok & 4 & 1,8 \\
\hline Doğum korkusu yaşama durumu & & \\
Evet & 150 & 68,1 \\
Hayır & 70 & 31,9 \\
\hline Gebelikte düzenli egzersiz yapma durumu & & \\
(Haftada en az iki gün yarım saat) & & \\
Evet & 87 & 39,5 \\
Hayır & 133 & 60,5 \\
\hline
\end{tabular}

Gebelikte yoganın faydalı olduğuna dair bilgisi olanların oran1 \%45 $(n=99)$ iken gebelerin \%33,6's1 $(n=74)$ yoganın sadece esnek kadınlara uygun olduğunu düşünmektedir. Gebelerin \%62,7'si $(n=138)$ gebelik döneminde yoga yapmanın esnekliği da, \%45,5'i $(\mathrm{n}=100) \quad$ gebelik stresini da, \%51,4'ü $(n=113)$ zihni boşaltmada etkili olacağını ve \%30,9'u (n=68) gebenin öz yeterliliğini arttırmada etkili olacağını düşünmekte iken yalnızca \%18,6'sı $(n=41)$ gebelik risklerini azaltmada etkili olabileceğini düşünmektedir. Gebelerin \%50,5'i $(n=111)$ gebelikte yoga yapmanın doğumu daha kolay gerçekleştirmede, \%52,3'ü $(n=115)$ doğumda nefesi daha etkili kullanmada, \%41,8'i (n=92) doğum dalgalarıyla başetmede, \%37,7'si (n=83) doğal doğum oranını arttırmada ve\%30,0'u ( $n=66)$ doğum süresini kısaltmada etkili olabileceğini düşünmektedir. Ayrıca gebelerin yalnızca \%28,2'si $(n=62)$ yoganın anne bebek ilişkisini arttırmada, \%22,3'ü (n=49) indüksiyonu ihtiyacını azaltmada, \%12,3'ü $(\mathrm{n}=27)$ prematür doğum riskini azaltmada, etkili olabileceğini düşünmektedir. Bu verilerin yanı sıra gebelerin \%36,4'ü $(n=80)$ gebelikte yoga yapmanın postpartum depresyon riskini azaltmada etkili olduğunu düşünürken, \%40,5'i $(n=89)$ yoga yapmanın maliyeti yüksek bir uygulama olduğunu düşünürken yalnızca \%26,4'ü $(n=58)$ yogayı evde kendi uygulayabileceğini düşünmektedir (Tablo III).

Tablo III. Gebelerin Gebelikte Yoga Hakkındaki Görüş ve Düşüncelerinin Dağılımı $(n=220)$

\begin{tabular}{|c|c|c|}
\hline Değişkenler & $\mathrm{n}$ & $\%$ \\
\hline $\begin{array}{l}\text { Gebelikte yoganın faydaları hakkında bilgi } \\
\text { sahibi olma durumu } \\
\text { Evet } \\
\text { Hayır } \\
\text { Fikrim yok }\end{array}$ & $\begin{array}{l}99 \\
40 \\
81\end{array}$ & $\begin{array}{l}45,0 \\
18,2 \\
36,8\end{array}$ \\
\hline $\begin{array}{l}\text { Yoganın sadece esnek kadınlara uygun } \\
\text { olduğunu düşünme durumu } \\
\text { Evet } \\
\text { Hayır } \\
\text { Fikrim yok }\end{array}$ & $\begin{array}{l}74 \\
84 \\
62 \\
\end{array}$ & $\begin{array}{l}33,6 \\
38,2 \\
28,2 \\
\end{array}$ \\
\hline $\begin{array}{l}\text { Yoganın esnekliği arttırdığını düşünme } \\
\text { durumu } \\
\text { Evet } \\
\text { Hayır } \\
\text { Fikrim yok }\end{array}$ & $\begin{array}{c}138 \\
27 \\
55\end{array}$ & $\begin{array}{l}62,7 \\
12,3 \\
25,0\end{array}$ \\
\hline $\begin{array}{l}\text { Yoganın gebelik stresini azaltmada etkili } \\
\text { olacağını düşünme durumu } \\
\text { Evet } \\
\text { Hayır } \\
\text { Fikrim yok }\end{array}$ & $\begin{array}{c}100 \\
24 \\
96\end{array}$ & $\begin{array}{l}45,5 \\
10,9 \\
43,6\end{array}$ \\
\hline $\begin{array}{l}\text { Yoganın zihni boşaltmada etkili olacağını } \\
\text { düşünme durumu } \\
\text { Evet } \\
\text { Hayır } \\
\text { Fikrim yok }\end{array}$ & $\begin{array}{c}113 \\
27 \\
80\end{array}$ & $\begin{array}{l}51,4 \\
12,3 \\
36,4\end{array}$ \\
\hline $\begin{array}{l}\text { Yoganın gebenin öz-yeterliliğini arttıraca- } \\
\text { ğını düşünme durumu } \\
\text { Evet } \\
\text { Hayır } \\
\text { Fikrim yok }\end{array}$ & $\begin{array}{c}68 \\
33 \\
119 \\
\end{array}$ & $\begin{array}{l}30,9 \\
15,0 \\
54,1\end{array}$ \\
\hline $\begin{array}{l}\text { Yoganın gebelikteki risk durumlarını (hi- } \\
\text { pertansiyon, preeklempsi, diyabet vb) } \\
\text { azaltabileceğini düşünme durumu } \\
\text { Evet } \\
\text { Hayır } \\
\text { Fikrim yok }\end{array}$ & $\begin{array}{c}41 \\
49 \\
130\end{array}$ & $\begin{array}{l}18,6 \\
22,3 \\
59,1\end{array}$ \\
\hline $\begin{array}{l}\text { Yoganın doğumu daha kolay gerçekleştir- } \\
\text { mede etkili olacağını düşünme durumu } \\
\text { Evet } \\
\text { Hayır } \\
\text { Fikrim yok }\end{array}$ & $\begin{array}{c}111 \\
42 \\
67\end{array}$ & $\begin{array}{l}50,5 \\
19,1 \\
30,5\end{array}$ \\
\hline $\begin{array}{l}\text { Yoganın doğum dalgalarıyla başetmede } \\
\text { etkili olacağını düşünme durumu } \\
\text { Evet } \\
\text { Hayır } \\
\text { Fikrim yok }\end{array}$ & $\begin{array}{l}92 \\
36 \\
92\end{array}$ & $\begin{array}{l}41,8 \\
16,4 \\
41,8 \\
\end{array}$ \\
\hline $\begin{array}{l}\text { Yoganın doğumda doğru nefes almada } \\
\text { etkili olacağını düşünme durumu } \\
\text { Evet } \\
\text { Hayır } \\
\text { Fikrim yok }\end{array}$ & $\begin{array}{c}115 \\
18 \\
87\end{array}$ & $\begin{array}{r}52,3 \\
8,3 \\
39,4\end{array}$ \\
\hline
\end{tabular}


Tablo III. (Devamı)

\begin{tabular}{|c|c|c|}
\hline $\begin{array}{l}\text { Yoganın akciğer kapasitesini geliştireceği- } \\
\text { ni düşünme durumu } \\
\text { Evet } \\
\text { Hayır } \\
\text { Fikrim yok }\end{array}$ & $\begin{array}{c}79 \\
30 \\
111\end{array}$ & $\begin{array}{l}35,9 \\
13,6 \\
50,5\end{array}$ \\
\hline $\begin{array}{l}\text { Yoganın doğumda indüksiyon ihtiyacını } \\
\text { azaltacağını düşünme durumu } \\
\text { Evet } \\
\text { Hayır } \\
\text { Fikrim yok }\end{array}$ & $\begin{array}{c}49 \\
42 \\
129\end{array}$ & $\begin{array}{l}22,3 \\
19,1 \\
58,6\end{array}$ \\
\hline $\begin{array}{l}\text { Yoganın doğal doğum oranını arttıracağını } \\
\text { düşünme oranı } \\
\text { Evet } \\
\text { Hayır } \\
\text { Fikrim yok }\end{array}$ & $\begin{array}{c}83 \\
31 \\
106\end{array}$ & $\begin{array}{l}37,7 \\
14,1 \\
48,2\end{array}$ \\
\hline $\begin{array}{l}\text { Yoganın doğum süresini kısaltacağını } \\
\text { düşünme durumu } \\
\text { Evet } \\
\text { Hayır } \\
\text { Fikrim yok }\end{array}$ & $\begin{array}{c}66 \\
40 \\
114\end{array}$ & $\begin{array}{l}30,0 \\
18,2 \\
51,8\end{array}$ \\
\hline $\begin{array}{l}\text { Yoganın anne bebek ilişkisini arttırdığını } \\
\text { düşünme durumu } \\
\text { Evet } \\
\text { Hayır } \\
\text { Fikrim yok }\end{array}$ & $\begin{array}{l}62 \\
62 \\
96\end{array}$ & $\begin{array}{l}28,2 \\
28,2 \\
43,6\end{array}$ \\
\hline $\begin{array}{l}\text { Yoganın prematüre doğum oranını azalta- } \\
\text { cağını düşünme oranı } \\
\text { Evet } \\
\text { Hayır } \\
\text { Fikrim yok }\end{array}$ & $\begin{array}{c}27 \\
57 \\
136 \\
\end{array}$ & $\begin{array}{l}12,3 \\
25,9 \\
61,8 \\
\end{array}$ \\
\hline $\begin{array}{l}\text { Yoganın doğum sonrası depresyon oranını } \\
\text { azaltacağını düşünme durumu } \\
\text { Evet } \\
\text { Hayır } \\
\text { Fikrim yok }\end{array}$ & $\begin{array}{c}80 \\
30 \\
110 \\
\end{array}$ & $\begin{array}{l}36,4 \\
13,6 \\
50,0\end{array}$ \\
\hline $\begin{array}{l}\text { Yoganın yan etkisi olduğunu düşünme } \\
\text { durumu } \\
\text { Evet } \\
\text { Hayır } \\
\text { Fikrim yok }\end{array}$ & $\begin{array}{c}29 \\
118 \\
73\end{array}$ & $\begin{array}{l}13,2 \\
53,6 \\
33,2\end{array}$ \\
\hline $\begin{array}{l}\text { Yoganın maliyeti yüksek bir uygulama } \\
\text { olduğunu düşünme durumu } \\
\text { Evet } \\
\text { Hayır } \\
\text { Fikrim yok }\end{array}$ & $\begin{array}{l}89 \\
71 \\
60\end{array}$ & $\begin{array}{l}40,5 \\
32,3 \\
27,3 \\
\end{array}$ \\
\hline $\begin{array}{l}\text { Yoganın evde uygulanabileceğini düşünme } \\
\text { durumu } \\
\text { Evet } \\
\text { Hayır } \\
\text { Fikrim yok }\end{array}$ & $\begin{array}{c}58 \\
110 \\
52\end{array}$ & $\begin{array}{l}26,4 \\
50,0 \\
23,6\end{array}$ \\
\hline
\end{tabular}

Gebelerin eğitim durumları ile yoganın gebeliğe uygun olduğunu düşünmeleri hakkında görüşleri arasındaki istatistiksel olarak anlamlı bir ilişki bulunmaktadır ( $p=0,003)$. Eğitim seviyesi arttıkça yoganın gebeliğe uygun olduğunu düşünme oranı da artmaktadır. Ayrıca gebelerin eğitim seviyesi ile yoganın gebeliğe faydaları hakkındaki bilgileri ve yogayı evde uygulayabilmelerini düşünmeleri arasında da anlamlı ilişki bulunmuştur (sırasıyla $p=0,000$ ve $p=0,023$ ). Eğitim seviyesi yükseldikçe gebelerin gebelikte yoganın faydaları hakkındaki bilgi sahibi olma durumları ve yogayı evde uygulayabileceklerini düşünme oranları artmaktadır (Tablo IV).
Tablo IV. Gebelerin Eğitim Durumları İle Yoga Hakkındaki Görüşlerinin İlişkisi $(\mathrm{n}=220)$

\begin{tabular}{|c|c|c|c|c|}
\hline \multirow{2}{*}{$\begin{array}{l}\text { Yoga Hakkındaki } \\
\text { Görüşleri }\end{array}$} & \multicolumn{4}{|c|}{ Eğitim Durumu } \\
\hline & Ortaöğretim & Lise & Üniversite & \multirow{2}{*}{$\begin{array}{l}\text { Test ve P } \\
\text { Değeri }\end{array}$} \\
\hline $\begin{array}{l}\text { Yoga gebeliğe uygun } \\
\text { mudur? }\end{array}$ & $n(\%)$ & $\mathrm{n}(\%)$ & $\mathrm{n}(\%)$ & \\
\hline Evet & $26(\% 30,6)$ & $26(\% 35,1)$ & $37(\% 60,7)$ & \multirow{3}{*}{$\begin{array}{l}X^{2}=16,022 \\
P=0.003\end{array}$} \\
\hline Hayır & $14(\% 15,5)$ & $14(\% 18,9)$ & $9(\% 14,8)$ & \\
\hline Fikrim yok & $45(\% 52,9)$ & $34(\% 45,9)$ & $15(\% 24,6)$ & \\
\hline \multicolumn{5}{|l|}{$\begin{array}{l}\text { Yoganın gebelikte } \\
\text { faydaları hakkında } \\
\text { bilginiz var mı? }\end{array}$} \\
\hline Evet & $26(\% 30,6)$ & $28(\% 37,8)$ & $45(\% 73,8)$ & \multirow{3}{*}{$\begin{array}{l}X^{2}=34,022 \\
P=0.000\end{array}$} \\
\hline Hayır & $15(\% 17,6)$ & $15(\% 20,3)$ & $10(\% 16,4)$ & \\
\hline Fikrim yok & $44(\% 51,8)$ & $31(\% 41,9)$ & $6(\% 9,8)$ & \\
\hline \multicolumn{5}{|l|}{$\begin{array}{l}\text { Yogayı öğrenen } \\
\text { gebenin evde kendi- } \\
\text { sinin uygulaması }\end{array}$} \\
\hline Evet & $15(\% 17,6)$ & $18(\% 24,3)$ & $25(\% 41,0)$ & \multirow{3}{*}{$\begin{array}{l}X^{2}=11,338 \\
P=0.023\end{array}$} \\
\hline Hayır & $45(\% 52,9)$ & $38(\% 51,4)$ & $27(\% 44,3)$ & \\
\hline Fikrim yok & $25(\% 29,4)$ & $18(\% 24,3)$ & $9(\% 14,8)$ & \\
\hline
\end{tabular}

\section{Tartışma}

Yapılan birçok çalışmada yoganın gebelik, doğum ve doğum sonu dönemde fiziksel, psikolojik ve mental yönden olumlu etkileri olduğu savunulmaktadır. Kusaka et al (2016), yapmış oldukları çalışmada gebelikte yoga yapmanın gebelikte yaşanan stres düzeyiyle ilişkisini değerlendirmiş ve gebelik döneminde yapılan yoganın stres düzeyini azalttığını saptamışlardır. Benzer şekilde yoganın gebenin stres düzeyini anlamlı oranda düşürdüğünü gösteren çalışmalar oldukça fazladır (Ratfish, 2018; Sharma \& Branscum, 2015; Curtis, Weinrib, \& Katz, 2012; Deshpande, et al., 2013). Çalışmamızda da kadınların yaklaşık olarak yarısı gebelikte yoga yapmanın stresi azalttığını düşünmektedir.

Gebelikte yoga uygulamalarında öğrenilen nefes teknikleri, doğum sırasında gebenin nefesini daha etkin kullanmasını, doğumu daha kolay ve bilinçli bir şekilde yönetmesini ve vücuduna daha uyumlu olarak doğumuna aktif katılımını sağlamaktadır. Normal doğum zamansız olsa da, önceden öğrenilen yoga doğum anında bireyin odaklanma ve sakin kalma yeteneğini kullanmasına yardımcı olmaktadır (Akarsu \& Rathfsch, 2018). Yapılan bir çalışma gebelikte öğrenilen ve doğumda uygulanan yoganın doğumda öz-yeterliliğin artması ve anne bebek bağlanmasında ve apgar skorunda artma gibi olumlu değişikliklere yol açtığını göstermiştir (Sharma \& Branscum, 2015). Çalışmamızda gebelerin yarısı gebelikte yoga yapmanın doğumu kolaylaştırmada etkili olduğunu düşünmektedir ancak gebenin öz-yeterliliğini arttırmada ve doğum sonu anne bebek bağlanmasında etkili olduğunu düşünenlerin oranı oldukça düşüktür. 


\section{Gebelikte Yoganın Faydaları}

Doğum öncesi dönemdeki duygusal stres ve anksiyete, prematür, preterm ve olumsuz nörogelişime sahip yenidoğan çıktıları ile ilişkilendirilmiştir (DunkelSchetter \& Tanner, 2012). Karnasih (2018) yoga yapan ve yapmayan gebeler arasında doğum ağırlı̆̆ı, doğum süresi ve doğumda ağrı skalasında anlaml farklılıklar olduğunu göstermiştir. Çalışmamızda gebelerin gebelikte yoga yapmanın yenidoğanın prematür veya preterm doğma riskini azaltmada ve doğum süresini kısaltmada etkili olduğunu düşünme oranı oldukça düşük düzeyde çıkmıştır. Maternal stres, doğum sırasındaki analjezi ve planlanmamış sezaryen doğumla ilişkilidir. $\mathrm{Bu}$ negatif doğum sonuçlarına ek olarak stres, gebeliğe bağlı hipertansiyon, preeklampsi, eklampsi, gestasyonel diyabetes mellitus, erken membran rüptürü gibi sorunlara yol açmaktadır. Gebelikte yoga yapma ile bu risklerin azaldığı literatürde vurgulanmaktadır (Sharma \& Branscum, 2015). Ancak çalışmamızda gebelerin yarısı gebelikte yoga yapmanın doğum dalgalarıyla başetmede etkili olduğunu düşünürken, çok az sayıda gebe yoganın gebelik risklerini önlemede etkili olduğunu düşünmektedir. Psikolojik ve fizyolojik sağlığa faydalı olduğu, genel kaygıyı azalttığı ve bazı durumlarda gebelerde birçok egzersizden daha iyi olduğu yapılan çalışmalarla desteklenmektedir (Riley \& Park, 2015; Ross \& Sue, 2010). Ayrıca yoga uygulanabilir, güvenilir ve maliyeti etkin bir yöntem olarak gebelik dönemine uygun olduğu belirtilmiştir (Deshpande, et al., 2013). Çalışmamızda gebelerin büyük bir çoğunluğu yoganın; yürüyüş, nefes egzersizi, pilates, yüzme gibi gebelik uygulamaları arasından en az uygun olduğu ve yoga yapmanın maliyetli bir uygulama olduğunu düşünmektedirler.

\section{Sonuç}

Yoganın gebelik, doğum ve doğum sonu süreçte olumlu çıktıları, uygulanabilir ve ekonomik olması nedeniyle gebeliğge uygun bir uygulama olduğu yapılan çalışmalarla desteklenmektedir. Bu kapsamda çalışmanın bulguları incelendiğinde yoga uygulamalarının olumlu sonuçlarına rağmen gebe kadınların konu ile ilgili bilgi ve bilinç düzeyinin istenen düzeyde olmadığı tespit edilmiştir. Doğum öncesi bakım önemli bir halk sağlı̆̆ı sorunudur ve bunları iyileștirmek için uygulanabilecek yaklaşımlardan birisi de gebelikte yoga uygulamasının yaygınlaştııılmasıdır (Sharma \& Branscum, 2015). Gebelik, doğum ve doğum sonu süreçler üzerindeki olumlu sonuçlarının farkında olunması, yoga uygulamalarının kullanılmasını sağlayarak anne ve bebeğin sağlık sonuçlarının daha iyi olmasına önemli katkı sunacaktır. Bu kapsamda özellikle ebelerin gebelere yönelik yoga alanında eğitimlerini ve çalışmalarını yoğunlaştırmasının, yoganın gebelik doğum ve doğum sonu dönemdeki olumlu çıktılarını destekleyecek uygulamalı araştırmalar yapması ile ebelik alanına katkı sağlanacağı düşünülmektedir.

\section{Kaynakça}

1. Akarsu, R. H., \& Rathfsch, G. (2018). Sihirli Bir Yol: Gebelik Yogas1. Smyrna Tip Dergisi , 57-61.

2. Alkan, E., \& Özçoban, F. A. (2017). Yoganın Gebelik, Doğum ve Doğum Sonuçları Üzerine Etkisi. Smyrna Tıp Dergisi, 64-71.

3. Başmeşe, Z. B. (2017). Stresli Gebelerin Stres Yönetiminde Yogaya İlişkin Deneyimlerinin Belirlenmesi. İzmir: Ege Üniversitesi Kadın Sağlığı ve Hastalıkları Hemşireliği Anabilim Dalı Doktora Tezi.

4. Chhajta, A. S. (2018). Yoga for a Blissful Birth. Mother and Baby, 60-63.

5. Curtis, K., Weinrib, A., \& Katz, J. (2012). Systematic Review of Yoga for Pregnant Women: Current Status and Future Directions. Hindawi Publishing Corporation Evidence-Based Complementary and Alternative Medicine, doi:10.1155/2012/715942.

6. Deshpande, C., Rakshani, A., Nagarathna, R., Ganpat, T., Kurpad, A., Maskar, R., . . . Sudheer, D. (2013). Yoga for High-Risk Pregnancy: A Randomized Controlled Trial. Annals of Medical Health Science Research, 3(3): 341-344.

7. Dunkel-Schetter, C., \& Tanner, L. (2012). Anxiety, depression and stressin pregnancy: implications for mothers, children, research,and practice. Current Opinion in Psychiatry, 25:141148.

8. Karnasih, I. (2018). The Effect Of Yoga Towards Birth Delivery Output. International Journal of Scientific \& Technology Research, 7 (12): 62-66.

9. Kumar, K., \& Patel, S. (2016). A study on the effect of Yoga and Diet-Control on Body Mass Index and Cholesterol Level of the Obese Youth. International Journal of Science and Consciousness, 2(1), 13-17.

10. Kusaka, M., Matsuzaki, M., Shiraishi, M., \& Haruna, M. (2016). Immediate Stress Reduction Effects of Yoga During Pregnancy: One Group Pre-post Test. Women and Birth, 29(5):e82-e88. doi: 10.1016/j.wombi.2016.04.003.

11. Marc, I., Toureche, N., Ernst, E., Hodnet, E., CBlanchet, Dodin, S., \& MM, M. N. (2011). Mindbody Interventions During Pregnancy for Preventing or Treating Women's Anxiety. Cochrane Library, 7.

12. Olieman, R. M., Siemonsma, F., Bartens, M. A., \& Honig, A. (2017). The Effect of an Elective Cesarean Section on Maternal Request on Peripartum Anxiety and Depression in Women with Childbirth Fear: A Systematic Review. BMC Pregnancy and Childbirth, 17(195).

13. Ratfish, G. (2018). Kadın Sağlığı İçin Yoga. Kadın Sağlı̆̆ Hemşireliği Dergisi, 22.

14. Riley, K. E., \& Park, C. L. (2015). How Does Yoga Reduce Stress? A Systematic Review of Mechanisms of Change and Guide to Future Inquiry. Health Psychology Review, 9(3), 1-30.

15. Riley, K., \& Drake, E. (2013). The Effects of Prenatal Yoga on Birth Outcomes: A Systematic Review of the Literature. Journal of Prenatal and Perinatal Psychology and Health , 28(1).

16. Ross, A., \& Sue, T. (2010). The Health Benefits of Yoga and Exercise: A Review of Comparison Studies. The Journal of Alternative and Complementary Medicine, 16(1), 3-12.

17. Sharma, M., \& Branscum, P. (2015). Yoga Interventions in Pregnancy:A Qualitative Review. The Journal Of Alternative And Coöplementary Medicine, 1-9. 
Z.B. Yurtsal, ark.

18. Thakur, J., Sharma, E., \& Masand, S. (2015). Yoga in Pregnancy: A Boon To Motherhood. Journal of Ayurveda \& Holistic Medicine, 3(6):121-128.

19. Wile, N. (2013). Benefits of Prenatal Yoga and Safe and Unsafe Postures and Activities. United Kingdom: Yoga Education Institute.
20. Yadav, S. K., \& Kumar, A. (2015). Importance of Yoga in Daily Life. Research Gate, DOI: 10.13140/RG.2.1.4538.3842. 